\title{
EDITORIAL
}

\section{Cambio climático y retroceso glaciar}

El calentamiento del sistema climático de la Tierra es inequívoco, desde la década de 1950 muchos de los cambios observados carecen de precedentes aun en los últimos decenios a milenios. La atmósfera y el océano se han calentado, los volúmenes de nieve y hielo han disminuido y el nivel del mar se ha elevado.

Entre 1992 y 2011, los mantos de hielo de Groenlandia y la Antártida han ido perdiendo masa, y es probable que la pérdida se haya precipitado mucho más rápido entre 2002 y 2011. Los glaciares, pasan por un deshielo global desde hace más de cien años y a una velocidad sin precedentes. Michael Zemp, líder del Servicio de Monitoreo Mundial de Glaciares (WGMS), sostiene que los glaciares observados pierden hoy entre medio metro y un metro de espesor de hielo cada año, caso que representa dos o tres veces más que el promedio del siglo pasado (1). El manto de nieve en primavera en el hemisferio norte sigue reduciéndose. Existe un nivel de confianza alto en cuanto a que las temperaturas del permafrost han aumentado en la mayoría de las regiones desde principios de la década de 1980 en respuesta al aumento de la temperatura en superficie y la alteración del manto de nieve.

En el Ártico, es muy probable que la superficie media anual del hielo marino haya disminuido durante el período 1979-2012 en un rango del $3,5 \%$ al 4,1 \% por decenio. La extensión del hielo marino en la zona ha disminuido en cada estación y en cada decenio sucesivo desde 1979, y es en verano cuando se ha registrado el mayor ritmo de disminución en la extensión media decenal. En la Antártida, es muy probable que la extensión media anual del hielo marino haya aumentado en un rango de entre el 1,2\% y el 1,8\% por decenio entre 1979 y 2012; sin embargo, existe un nivel de confianza alto respecto a que existen marcadas diferencias regionales en este continente, con un aumento de la extensión en algunas regiones y una disminución en otras. Durante el período 1901-2010, el nivel medio global del mar se elevó 0,19 m (de 0,17 a $0,21 \mathrm{~m}$ ). Desde mediados del siglo XIX, el ritmo de la elevación del nivel del mar ha sido superior a la media de los dos milenios anteriores (2).

El retroceso de la masa glaciar en las montañas chinas, por ejemplo, están identificadas como muy vulnerables al cambio climático, sobre todo en el oeste de China. Durante el período 1961-2007, aproximadamente el $92 \%$ de las zonas de glaciares tenía una vulnerabilidad leve, hoy el 41,2 \% de tales áreas está en los niveles fuerte y muy fuerte de vulnerabilidad. En general, la vulnerabilidad de los glaciares muestra una tendencia decreciente entre el 2030 y el 2050, pero los glaciares en Altai, Tianshan, Kunlun, las zonas central y occidental de la montaña Qilian, zonas central y oriental del Himalaya, y el sureste del Tíbet, seguirán siendo clasificadas en los niveles fuerte y muy fuertes de vulnerabilidad.

Los glaciares de China eran relativamente muy vulnerables en el período 1961-2007, y se consideran que la topografía y la alta sensibilidad de los glaciares al cambio climático son las razones de esta situación. Además de los factores topográficos, se considera que las variaciones en las precipitaciones podrían convertirse en un factor crucial que afecta la vulnerabilidad de los glaciares en los años 2030 y 2050 (3).

También en Perú, entre el 2003 y el 2011 las mediciones de balance de masa realizadas en los glaciares Yanamarey y Artesonraju en la Cordillera Blanca, en Huaraz, mostraron en el caso del Yanamarey pérdidas de área en el frente, y en los bordes laterales hasta la parte alta del glaciar.

A pesar de la desaceleración del aumento de la temperatura y un aumento en la precipitación, la retirada de los glaciares ha continuado a un ritmo elevado en los últimos treinta años.

La precipitación y la temperatura pueden afectar el proceso de acumulación. El aumento de la precipitación observada durante las estaciones húmedas conduciría a un aumento de la precipitación sólida en el área de acumulación y, por tanto, un balance de masas más positivo anual en caso de precipitación que caiga en forma de nieve (4); por 
ejemplo, se encontró que en escalas de tiempo interanuales, la variabilidad de la precipitación parece ser el principal motor de las fluctuaciones de la masa glaciar en la Cordillera Blanca. Por otro lado, el aumento de temperaturas de aire durante los episodios de precipitaciones conduce también a un aumento de la línea de nieve. Sin embargo, el aumento de la temperatura del aire en los últimos treinta años es particularmente dominante en la temporada de junio a noviembre, relativamente seca, en la que las precipitaciones son más bien escasas.

Las precipitaciones en la Cordillera Blanca han aumentado significativamente entre 1980 y 2012 , lo que llevaría a un balance de masa más positivo si la precipitación cae en forma de nieve condición que evidencia que los glaciares han continuado retrocediendo desde los ochenta.

La disminución de la superficie glaciar es particularmente alta para los glaciares de baja altitud y glaciares aislados como el Yanamarey y Pastoruri. Hay estudios que informan de los diferentes escenarios de retiro para los pequeños glaciares con elevaciones máximas debajo de 5400 m s. n. m. y los grandes glaciares con la máxima elevación por encima de tal altitud.

Los cambios de temperatura y precipitación desde los ochenta probablemente no explican por completo el fuerte retroceso de los glaciares durante los últimos 30 años. Por ello es posible que el reciente retroceso de los glaciares aún puede ocurrir en respuesta a la fuerte subida de temperatura de más de $0,3^{\circ} \mathrm{C}$ por década antes de 1980, especialmente en la década de 1970.

En general, los glaciares con bajo espesor del hielo en la línea de equilibrio y grande ablación anual en la lengua del glaciar tienen tiempos de respuesta menores a perturbaciones climáticas que las grandes glaciares. Existen mediciones y estimaciones de espesor de hielo y tasas de ablación anuales para algunos glaciares en la Cordillera Blanca (por ejemplo Artesonraju) y permiten estimar un tiempo de respuesta del orden de diez a cuarenta años. Por lo tanto, el fuerte retroceso de los glaciares observado durante las últimas tres décadas puede incluir una señal del aumento de la temperatura antes de la década de 1980, en función del glaciar. La subida, temperatura moderada durante los últimos treinta años, puede haber inducido forzamiento adicional. Sin embargo, la interpretación de las respuestas de los glaciares de forzamiento climático es un reto, ya que algunas fluctuaciones climáticas ocurren en escalas de tiempo más corto que los tiempos de reacción y, en consecuencia, la respuesta observada de un glaciar puede ser una reacción a un gran número de causas superpuestas (5).

\section{Referencias bibliográficas:}

1. Gubin A. Glaciares de todo el mundo desaparecen, y a velocidad sin precedentes. La Gran Época. [Online]. 2015Ag. 4. Disponibleen: http://www.lagranepoca.com/cienciay-tecnologia/noticias/14013-glaciares - de - todo-el-mundo-desaparecen$y$-a-velocidad-sin-precedentes.html

2. Panel Intergubernamental de Cambio Climático. Cambio climático 2014, informe de síntesis, resumen para responsables de políticas. Ginebra: Panel Intergubernamental de Cambio Climático; 2014.

3. Jian-Ping $Y$, Yong-Jian D, Shi-Yin L, ChunPing T. Vulnerability of mountain glaciers in China to climate change. Advances in Climate Change Research. 2015; 6(1).

4. Vuille M, Kaser G, Juen I. Glacier mass balance variability in the Cordillera Blanca, Peru and its relationship with climate and the large-scale circulation. Glob. Planet Change. 2008; 64.

5. SchauweckerS, RohrerM, Acuña D, Cochachin A, Dávila L, Frey $\mathrm{H}$, et al. Climate trends and glacier retreat in the Cordillera Blanca, Peru, revisited. Global and Planetary Change. 2014; 119(1).

Wilfredo Bulege Gutiérrez

Editor 